\title{
SYMPOSIUM
}

\section{The profile and context of the epidemics of sexually transmitted infections including HIV in Zimbabwe}

\section{J Decosas, N Padian}

Sex Transm Infect 2002;78(Suppl I):i40-i46

Zimbabwe has widespread and widely disseminated epidemics of most major sexually transmitted infections (STI) including HIV. This epidemiological situation is examined from a broad historical perspective, exploring the interactions between the population incidence of STI and the social profile of the country. The results suggest opportunities for upstream prevention efforts. Examples of these include: integration of prevention with care and social support; increasing general communication and openness about sexuality; economic support initiatives including income generating and micro-credit programmes, offering living accommodations for families in cities, mines, and military camps; and programmes focusing on adolescents before they become sexually active.

See end of article for authors' affiliations

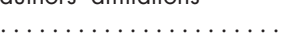

Correspondence to: Dr J Decosas, Southern African AIDS Training Programme, Box 390 Kopje, Harare, Zimbabwe: decosas@satregional.org

Accepted 29 November 2001 ike all epidemics of infectious disease, epidemics of sexually transmitted infections (STI) -move through different phases in their natural history. These phases are defined by changing incidence and prevalence, by changes in the profile of vulnerable populations, by a changing social and cultural environment, and by the effects of public health interventions. ${ }^{12}$ Surveillance of HIV has been expanded in recent years to include the surveillance of behavioural changes. ${ }^{3}$ Although this captures some of the environmental factors that determine the shape of HIV epidemics, it largely retains the individual as the unit of analysis and therefore maintains a narrow analytical and strategic focus for interventions.

Widening the focus of surveillance and intervention monitoring to include environmental and ecological variables is complicated by the historic dimension of the interaction between the epidemic and its environment. There are, however, examples showing that information about environmental determinants of health can be successfully triangulated with epidemiological data to arrive at a better understanding of what drives an epidemic and how to confront it. One such example in the STI field is an analysis of the social ecology of syphilis in the Southern USA by Thomas et al. ${ }^{4}$ A conceptual framework of determinants and interventions in response to HIV epidemics was recently published by Barnett and colleagues. ${ }^{5}$ It is presented with some modifications in fig 1 .

In this paper we synthesise available and readily accessible information to reconstruct the recent social, behavioural, and epidemiological history of STI in Zimbabwe.

\section{THE POLITICAL, ECONOMIC, AND SOCIAL CONTEXT}

The largest ethnic group in Zimbabwe is formed by the Shona people, who have inhabited the territory of the modern republic for more than 1000 years and who comprise about $74 \%$ of its population. The second largest ethnic group are the Ndebele, whose pastoralist forefathers invaded the territory in the 1850s, establishing a kingdom in the area today known as Matabeleland. The Ndebele make up about $18 \%$ of the population. Other African ethnic groups such as the Tonga, Shangaan, and Venda are small minorities. Europeans started to colonise and settle in the territory around 1890, and today make up less than $1 \%$ of the total population. ${ }^{6}$

In order to establish commercial farming, the European colonisers displaced the majority of the indigenous farming population into infertile lands that are today's Communal Areas, laying the foundations of the current land disputes in Zimbabwe. Decolonisation only started in 1980, considerably later than in most African countries. It has been a protracted and sometimes violent process characterised by political instability and ethnic tension. As a consequence, community cohesion in many rural areas is low.

The post-independence economic history of Zimbabwe is characterised by a 20 year decline in economic performance. From 1990 to 1994 Zimbabwe underwent a poorly conceived economic structural adjustment programme that had the perverse effect of speeding up the deindustrialisation of the country. At independence, Zimbabwe had one of the highest levels of social inequality in the world. There have clearly been major social equity achievements since then, but the unequal distribution of wealth has not improved except to the extent that most of the population have become poorer ${ }^{7-9}$

In 1995, at the time when the country experienced the full impact of the failed economic structural adjustment programme, the government of Zimbabwe conducted a national poverty survey.$^{10}$ The report provides a snapshot of poverty in a period of severe economic depression. After 1995 there was a brief economic recovery. However, by 1999 the economy was again severely depressed, and poverty had become even more prevalent.

The survey reported that the level of poverty was highest in the communal lands, where $84 \%$ of the population lived below the basic needs poverty line, followed by resettlement areas and 


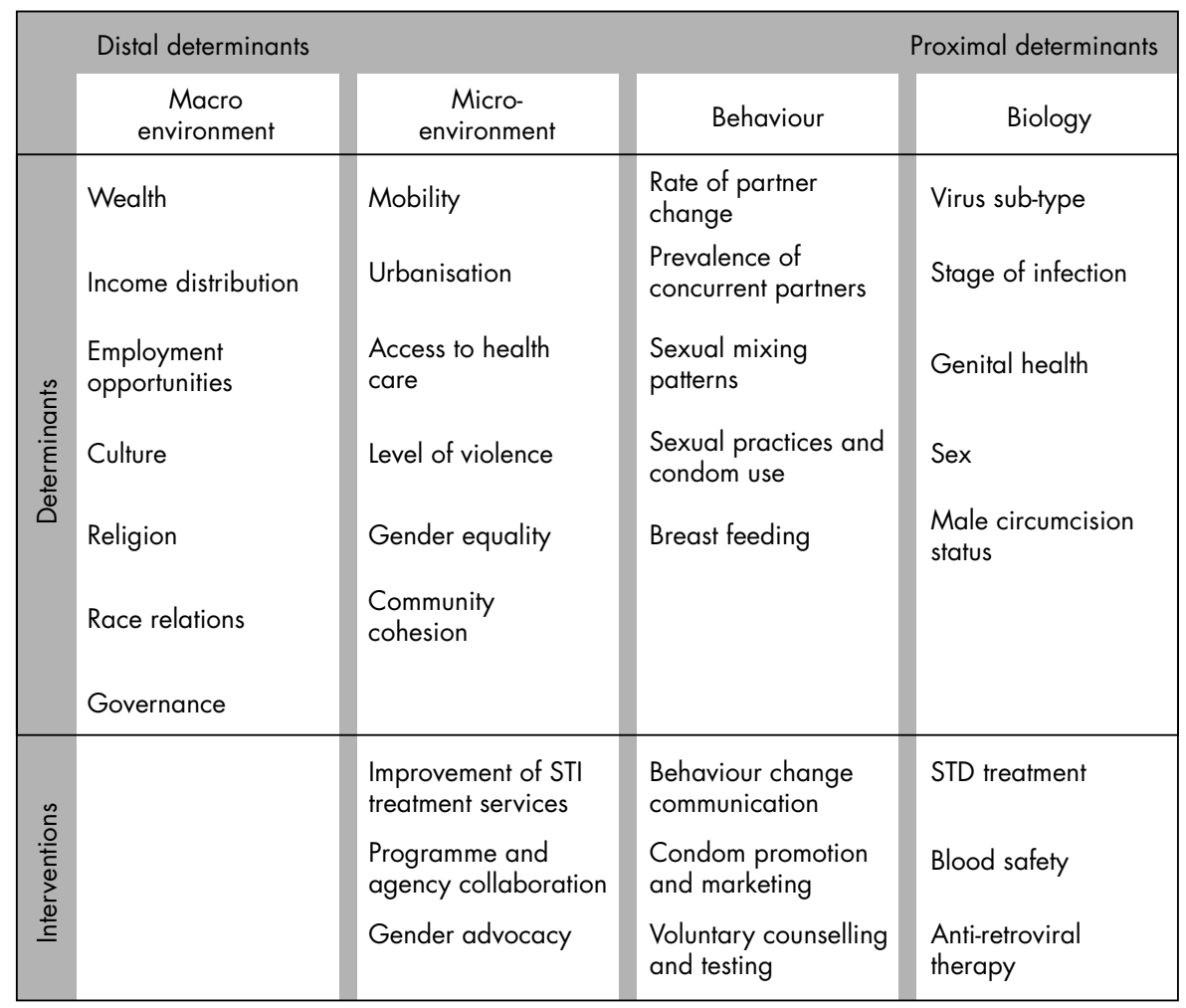

Figure 1 Framework of determinants and interventions in HIV epidemics.

Modified from: Barnett T, Whiteside A, Decosas J. The Jaipur Paradigm: A conceptual framework for understanding social susceptibility and vulnerability to HIV. (South African Medical Journal, 2000)

areas with small scale commercial farms (70\% poor), large scale commercial farming areas (57\% poor), and urban areas ( $39 \%$ poor). Like most poverty studies, the survey also found a major gender dimension in the distribution of poverty. Female headed households were on average poorer than male headed households, an indication of the strong interaction between gender and poverty. The very detailed district specific data of the poverty survey allow a comparison between the HIV prevalence in the 23 sentinel sites reported in $1997^{11}$ and the proportion of people found to be living in poverty in the areas surrounding these sites in 1995. As fig 2 shows, there is no association between poverty and HIV prevalence at this level of analysis. In addition to gender, issues such as mobility and migration as well as social norms with regard to sexual behaviour (both discussed below) clearly modify this relationship. Thus the relation between these two variables is obviously more complex.

A major social variable to be considered in an analytical and programmatic approach to STI is human mobility. As elsewhere, Zimbabwe has sites of high STI prevalence associated with major transport routes. Figure 3 shows HIV prevalence rates recorded in antenatal clinics at two of the major border posts linking Zimbabwe to the sea ports of Mozambique and South Africa. ${ }^{112}$ Furthermore, Zimbabwe has a colonial legacy of international and national circulatory labour migration that is gender segregated. This distorts the gender balance and thus the family structure as well as sexual relations in all locations, ${ }^{13}{ }^{14}$ and is a major contributor to the population risk of STI transmission. Lastly, Zimbabwe is a country that is still reorganising itself after a very long and disruptive colonial period. This involves extensive resettlement, including rural to urban migration to reunite previously separated families. It is not clear if and to what extent this resettlement contributes to the risk of STI epidemics. It is, however, certain that any programme response has to take this type of mobility into consideration.

Shona and Ndebele societies are both patriarchal and patrilineal. Like all patrilineal societies, they impose strict controls

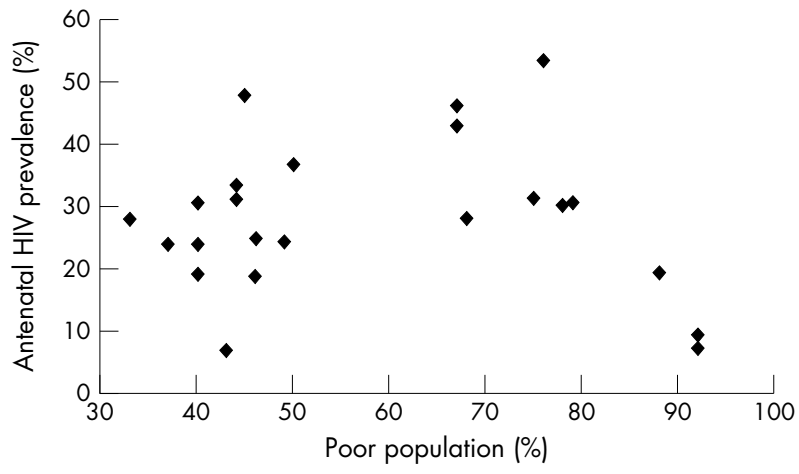

Figure 2 HIV prevalence in sentinel surveys among pregnant women (1997), and proportion of population living below the poverty line (1995) in the location of the 23 sentinel sites.

on female sexual behaviour because this is the only way to assure the continuity of the male lineage. There is a much more liberal attitude towards male sexual behaviour. ${ }^{15}$ Formal polygyny, although legal in Zimbabwe, is rare. ${ }^{16}$ Nevertheless, many Zimbabwean men report having a second wife. Presumably these are informal unions, and in many cases the "second wife" may actually be a euphemism for a series of casual sexual relationships. The institution of polygamy thereby provides an environment of tolerance for men to engage in multiple parallel sexual relationships.

Indirectly related to the institution of polygamy is the tolerance by traditional Shona society of intimacy between married men and their wife's younger sisters. ${ }^{17}$ This tolerance extends to the relation between male members of the husband's household and unmarried female members of the wife's household. It is not a licence for sexual intercourse, but allows for a level of sexual playfulness and innuendo. In traditional rural society, the tolerance can be understood in the context that the wife's younger female relatives were the 
first to be considered for marriage as a second wife, or as a "replacement" wife should the first marriage be infertile. In modern urban society, this tolerance has become a risk factor for sexual harassment and abuse of young girls.

\section{SEXUAL NORMS AND SEXUAL BEHAVIOUR}

Women usually start looking for husbands in their late teens. Casual sexual partners before marriage are not socially sanctioned and are indeed quite rare. Men, on the other hand, are not considered to be ready for marriage before their mid to late twenties, and are expected to have had several sexual partners before marriage. ${ }^{1819}$ This explains the discrepancies in numbers of sexual partners among men and women. In the majority of studies in Zimbabwe, 30-50\% of men reported having several concurrent sexual partnerships, compared with less than $5 \%$ of women.

Multiple concurrent partnerships among young men reflect, to a large extent, casual sexual contacts, including contact with sex workers, who report a high level of condom use. ${ }^{20}$ More important than the differences in number of partners is the age difference between partners. In a recent study by Gregson and colleagues, ${ }^{18}$ most women in rural Zimbabwe reported that their last sexual partner was between four to nine years older. This would, in most cases, be their husband or regular partner. HIV prevalence among young women increased significantly with increasing age of their male partner. Young men reported that their last sexual partner was between one and four years younger. The age difference was not as marked because a large proportion of these partners would have been casual sexual encounters.

A large study of structured interviews and focus group discussions conducted in 1991 and 1992 in a rural area of Zimbabwe confirmed the marked double standard in acceptable sexual norms. There was a high level of tolerance for men having concurrent sexual partnerships but none for women. The idea that men are natural polygamists and that there is a perceived harmful effect of prolonged sexual abstinence for men was common. Because of these social norms, the number of sexual partners among women may be underreported. ${ }^{21}$

In 1992, Wilson et al estimated that approximately $10 \%$ of the female population in Bulawayo, Zimbabwe's second largest city, had engaged in full or part time sex work at some time in their lives. ${ }^{22}$ However, most studies of sex work in Zimbabwe report that sex workers have low average numbers of clients. $^{202324}$ There is obviously a large grey area between "commercial" and "compensated" sex that is open to wide differences in interpretation. There is evidence that worsening economic conditions are making sex in exchange for money or material goods more common. ${ }^{21}$ In 1989 about half of the commercial sex acts in Zimbabwe were not protected by a

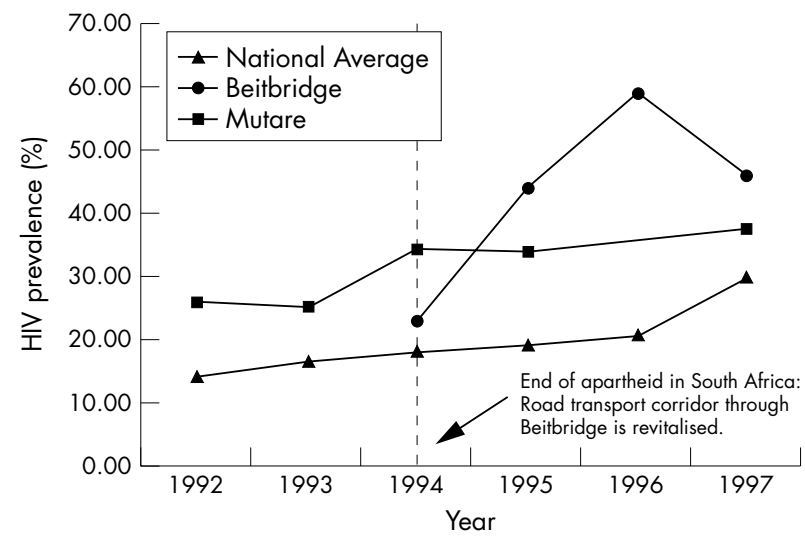

Figure 3 HIV prevalence among pregnant women at sentinel sites in border towns and average rate among all sites in Zimbabwe. condom. ${ }^{24}$ Since then, there have clearly been dramatic changes. In 2000, a behavioural survey among truck drivers, miners, and female sex workers found that condom use during commercial sex was almost universal. ${ }^{20}$

There is mounting evidence that condom use in Zimbabwe has increased in the last few years, especially among young people and in commercial sex. Both male and female condoms are being marketed very aggressively and are widely available in urban settings and on many commercial farms. Availability in rural areas and on some commercial farms is still problematic. Increased general awareness of the epidemic and prevention messages about the effectiveness of condoms has undoubtedly also contributed to this trend. Overall, however, condom use remains quite low. In the 1999 Zimbabwe Demographic and Health Survey (ZDHS) ${ }^{25}$ only $2 \%$ of women reported that they were currently using condoms. The proportion of women who had ever used a condom increased slightly from $13 \%$ in the 1988 ZDHS to only $18 \%$ in 1999 . Condom use rates were higher among younger, educated women in urban areas and among women who had no children or only one child. In contrast, more than half of the men had ever used a condom and $14 \%$ were current users. Among married men only $6 \%$ reported current condom use. The sex difference can again be explained by the widely differing sexual norms and the highly asymmetric patterns of sexual networking between men and women. In one qualitative study in 1998, Gregson et al reported that the majority of male focus group participants considered condom use inappropriate in stable unions. ${ }^{26}$

Traditionally, grandmothers and aunts discussed sexual matters with adolescent girls while grandfathers and uncles discussed these matter with teenage boys. Such traditional sex education has become rare, in part because there is the assumption that it occurs in the schools. ${ }^{21}$ In fact, most teenagers hear about sex from peers or from the media. In the male sexual behaviour and STD risk awareness study ${ }^{27}$ more than $75 \%$ of men in the 27 to 39 year age group reported that they discussed sex with their wives. These discussions were much less common among men older than 40 or younger than 27 .

Penetrative penile-vaginal sex is most common, while oral and anal sex are rarely practised. ${ }^{21}$ A recent review of traditional intravaginal practice ${ }^{28}$ cited six studies from Zimbabwe. Most reported that the insertion of herbs to tighten or dry the vagina or other practices of vaginal cleaning and wiping were almost universal. In a prospective study in Harare, women who used vaginal desiccants or who inserted herbs before sex were more likely to have STD symptoms and abnormal cervical cytology. ${ }^{23}$ Several studies report that men encourage and prefer their partners to use vaginal drying agents, yet this preference is expressed primarily by older men. ${ }^{27}{ }^{29}$ Concurring with this finding is a 1994 report from rural Matabeleland showing that all older women knew about vaginal drying agents, but none of the younger girls did. ${ }^{21}$

Table 1 reports on the frequency of factors and behaviours that place urban women in Zimbabwe at risk for STI. It was constructed from data obtained from 611 women in Harare seen in family planning or primary care clinics and enrolled in one of two studies: a study of vaginal drying agents completed in $1998,{ }^{23}$ and a study of the acceptability of barrier contraceptives completed in 2000 and not yet published (CDC grant No U64/CCU 913418).

\section{EPIDEMIOLOGY OF STI EXCLUDING HIV}

The national health information system of the Ministry of Health collects annual statistics of STI diagnoses in public sector facilities. The information is based on syndromic diagnosis and reported in the four categories of genital ulcers, urethral discharge, neonatal ophthalmia, and "other STI". The contribution of neonatal ophthalmia to the summary statistic is negligible. Approximately 1500 outpatient facilities are listed in the reporting system, of which approximately 1200 
Table 1 Sexual risk behaviour of women in family planning and primary care clinics

\begin{tabular}{ll}
\hline Factor & Frequency \\
\hline Ever received gift in exchange for sex & $17 \%$ \\
Ever forced to have sex with steady partner & $22 \%$ \\
Ever forced to have sex with non-steady partner & $5 \%$ \\
Steady partner lives with you half the time of less & $26 \%$ \\
Certain that steady partner has other partners & $35 \%$ \\
Partner had STD symptom (urethral discharge, warts, & $27 \%$ \\
sore, bubo) & 3 \\
Average number of partners, lifetime & $17(1-90)$ \\
Average monthly frequency of sex (range) & $64 \%$ \\
On hormonal contraception & $10 \%$ \\
Ever used condom in last three months & $24 \%$ \\
Partner intoxicated during sexual intercourse more than & \\
half the time & \\
\hline
\end{tabular}

submit annual reports. Many of the remaining facilities may not be functioning or have a very low volume of activity. The problems with using institution based data are well known. Usage rates of public health care facilities for treatment of STI vary widely on the basis of sex, social status, wealth, ethnicity, quality of service, and rural-urban location. It is therefore not useful to make inferences on these data beyond an examination of trends in STI incidence. The most recent annual data of total STI diagnoses per year obtained from the Ministry of Health are presented in table 2 .

Although these data are not sufficient to calculate rates, they do show that the number of reported STIs in Zimbabwe is declining. The decline is not rapid, but it is probably real. It has to be interpreted in the context of an increasing use of public facilities for health care because of increasing poverty, and in the context of increasing diagnosis and reporting of STI because of an extensive training programme of health workers in syndromic STI management. Behaviour change, such as the increased condom use reported above, may have also contributed to these trends. Reporting for 1999 is still incomplete; however, it is the only year for which we obtained syndrome specific reports. Among the 727788 cases reported, there were 173453 diagnoses of genital ulcer, 165492 diagnoses of urethral discharge, 6096 diagnosis of neonatal ophthalmia, and 364949 diagnoses of "other STI", including many of the vaginal discharge syndromes that are generally not sexually transmitted. Based on the estimate that there are currently about 2.6 million men in the age group of 15-49 in Zimbabwe, we calculate a "lowest estimate" that sexually active men in Zimbabwe have a $6 \%$ annual risk of contracting an STI causing urethral discharge. In contrast, a study conducted among women seen in a family planning in clinic in Harare ${ }^{30}$ documented laboratory confirmed diagnoses of chlamydia

Table 2 Number of diagnosis of STI reported to the Ministry of Health

\begin{tabular}{lc}
\hline Year & STI Diagnoses \\
\hline 1989 & 1078293 \\
1990 & 963436 \\
1991 & 1240596 \\
1992 & 878366 \\
1993 & 879307 \\
1994 & 813696 \\
1995 & 873218 \\
1996 & 864494 \\
1997 & 828876 \\
1998 & $\mathrm{n} / \mathrm{a}$ \\
1999 & 727788 \\
\hline n/a, not available. &
\end{tabular}

and gonorrhoea in only about $2-3 \%$ of the sample. Trichomonas infections, on the other hand, appear to be very common and most studies among women report a prevalence of $10-15 \%$. The contribution of trichomonas to the aetiology of urethral discharge in males in Zimbabwe is not known but may be significant.

The reported distribution of STD prevalence is consistent with the high level of asymmetry in sexual networking reported in behavioural studies in Zimbabwe. Young men have a highly diversified network of sexual partners that involves only a relatively small proportion of young women. The proportion of sex within this network that is commercial depends greatly on the definition of commercial sex. However, as sex within this network is increasingly protected by condoms, the incidence of STI is starting to decline in the country. In Harare, a reduction of nearly $60 \%$ of syndromically diagnosed STI episodes was reported between 1992 and 1996. In Chitungwiza, a large township adjacent to Harare, STI episodes declined by almost 50\% between 1993 and 1996. However, cases of vaginal discharge syndrome in Harare increased from 12879 in 1998 to 15384 in 1999. ${ }^{31}$

Data on vaginal discharge syndromes and on "other STI" which include a very large proportion of vaginal discharge syndromes are difficult to interpret. Non-specific bacterial vaginosis may contribute more to the population attributable risk for HIV transmission than all other STI, particularly in Southern Africa. ${ }^{32}$ The causes of bacterial vaginosis may include the use of vaginal drying agents, douching, or other inappropriate hygiene practices. Bacterial vaginosis may also be related to diet - or what we consider to be bacterial vaginosis may actually represent normal genital flora in this population. In two different studies in Harare, more than 30\% of women seen at a family planning clinic had bacterial vaginosis. ${ }^{23} 34$

There is also increasing evidence of a high prevalence of viral STI in Zimbabwe. In a recent study of 3500 factory workers in Harare, HSV-2 infection, diagnosed serologically, was found among $35.7 \%$ of subjects without HIV infection and among $85 \%$ of subjects with HIV infection. The annual incidence of HSV-2 infection in this population was $6 \% .^{35}$ Another study reported that $22 \%$ of women recruited in family planning clinics had abnormal PAP smears at a baseline visit. The majority of these abnormalities were CIN I or II; however, nearly $20 \%$ of women with abnormal cytology had frank cervical cancer. ${ }^{23}$

\section{EPIDEMIOLOGY OF HIV}

The national prevalence of HIV infection among adults in the 15 to 49 year age group increased from about $9 \%$ in 1990 to an estimated $25 \%$ in 1999 in a relatively linear progression. ${ }^{11}$ The estimate is derived from a large number of sentinel surveillance sites in antenatal clinics. The surveillance system used to ensure excellent coverage of the entire country, but its quality has deteriorated significantly since 1997. Sentinel data based on approximately 300 tests per site are still available for about 20 sites in 1997. All later estimates are based on mathematical projections and incomplete information. As in all countries, the epidemic is patchy, with the prevalence ranging from $7 \%$ to $53 \%$ at different sites. However, in contrast to many other countries, there is no evident urban-rural differential. The HIV prevalence in the major urban centres is equivalent or only slightly higher than the national average.

The primary age groups infected with HIV are women in their twenties, men in their thirties, and children under five. A population survey of close to 10000 people in rural Manicaland between 1998 and 2000 found peak HIV prevalence rates of close to $50 \%$ among women aged 23 to 25 and among men aged 30 to $34 .{ }^{18}$ The survey also found that women in the 17 to 24 year age group were four times more 
Table 3 Age specific HIV prevalence among 14112 pregnant women in Harare in 1998 and 1999

\begin{tabular}{ll}
\hline Age range & HIV prevalence \\
\hline$<20$ & $20 \%$ \\
$20-24$ & $31 \%$ \\
$25-29$ & $43 \%$ \\
$30-34$ & $44 \%$ \\
$35-39$ & $33 \%$ \\
$>40$ & $25 \%$ \\
\hline
\end{tabular}

Source: ZVITAMBO. ${ }^{35}$

likely to be HIV positive than men. However, the lifetime risk of acquiring HIV was about the same for both sexes.

Among the antenatal HIV sentinel surveillance sites only Harare provided age details on prevalence rates up to 1995. At that time $26 \%$ of pregnant women under the age of 20 tested positive for HIV; among those aged 15 to 17 the rate was $28 \%{ }^{12}$ However, the more recent ZVITAMBO trial of prevention of maternal to child transmission in Harare tested 14112 women within 72 hours of obstetric delivery in 1998 and 1999. Overall, 33\% of the women were infected with HIV, but the infection rate for women under 20 years of age was only $20 \%{ }^{36}$

The age specific HIV prevalence rates reported by this study are presented in table 3. The data from the 1995 sentinel survey in Harare are not representative enough to compare with the HIV prevalence data collected by ZVITAMBO. However, the apparent decline in HIV prevalence in the young age group and the suggestion of an "ageing profile" in the group of HIV infected women in the ZVITAMBO study suggests that the incidence of HIV in Harare may have started to fall. This would be consistent with published findings of increasing condom use and decreasing incidence of other STIs.

HIV prevalence among sex workers has only been reported in a single study of 147 women in Harare in 1995, where an HIV prevalence of $86 \%$ was found. ${ }^{37}$ Extensive information was, however, collected among STD patients in 30 different sites between 1990 and 1995. The range of HIV prevalence in this group was $24-60 \%$ in 1990 and $43-88 \%$ in $1995 .{ }^{12}$

\section{HEALTH SERVICES AND SPECIFIC STI AND HIV RELATED PROGRAMMES}

The Government of Zimbabwe Poverty Assessment survey asked 16000 respondents what type of facility they visited for any illness in the preceding month. ${ }^{10}$ The results do not vary much from the national average across poverty lines and between provinces. Of the population surveyed, $32 \%$ did not visit any facility, $1 \%$ consulted a traditional healer, $1 \%$ consulted some other alternative healer, $7 \%$ went to a private clinic or hospital, and $58 \%$ to a public facility. Public clinics and hospitals in Zimbabwe include the Ministry of Health facilities, the clinics operated by rural and municipal councils, and mission clinics and hospitals. Private consultation is five times more common in urban than in rural areas, while the rural population is much more likely to visit a mission facility, but this is primarily a reflection of the location of these institutions.

The survey results indicate that the public health care system in Zimbabwe is by far the largest health service provider, and that traditional and alternate healers play a very minor role. The situation may be somewhat different in the care for STI and in terminal care for people with AIDS, but in general, the public health care system in Zimbabwe has more weight than in many other African countries.

A health sector review commissioned by the government of Zimbabwe and the European Commission in 1997 estimated that there were about 1200 public health care facilities in
Zimbabwe, 1060 primary care or entry level facilities (rural health centres, town clinics, and rural hospitals), and 140 public hospitals at the first, second, and third referral level, including several operated by Catholic and Protestant mission. ${ }^{38}$ The referral chain established by the tiered system of care (primary, secondary, and tertiary levels) functions poorly. Lower levels of care are often bypassed. Care provided at the entry level is perceived to be of low quality. Rural health centres do not have a physician in attendance and there is a shortage of nurses. Opening hours are often restricted or patients are attended by nursing aides. Rural health centres frequently experience drug shortages and many do not have water, electricity, or a telephone to communicate with the district hospital. The physical state of health care facilities is variable.

Zimbabwe's postindependence achievements in public health, primary care, and prevention are exemplary and were used extensively as examples of "good health at low cost." Despite a decade of crisis and hardship, many of these achievements, such as high childhood vaccination rates, continue to be maintained. The system, however, is clearly strained. Since the mid-1990s the government of Zimbabwe, with support of several key international donors, has embarked on an ambitious restructuring of health services. The objective of the reform is to decentralise budgets and devolve decision making to the health districts and thereby revitalise the system. This initiative also means a gradual dismantling of the operational aspects of centralised vertical disease control and prevention programmes, including government programmes to prevent HIV and to control STI. Although a decentralised approach, developed and implemented at the district level, has a better chance of being effective, the transition from one system to another in a time of severe economic hardship is likely to result in serious programme gaps, at least temporarily.

In addition to Government health services, there are several hundred intervention projects and programmes on STI, HIV, and AIDS in Zimbabwe. These range from the support of voluntary counselling and testing sites to policy development and implementation. Most of these programmes are dependent on foreign donors to fund their most basic operations. UNAIDS maintains an inventory of all donor funded programmes on HIV and AIDS with more than 125 current entries. ${ }^{39}$ Twenty two international agencies are listed as the sponsors of the largest programmes. These include bilateral development agencies, United Nations agencies and programmes, international financial institutions, and international non-governmental organisations (NGOs) and federations.

Many externally funded programmes include direct service provision through existing government agencies (such as STI diagnosis and treatment programmes at government hospitals, voluntary counselling and testing (VCT) services at hospitals, and direct observed treatment for tuberculosis). Government agencies also benefit from procurement support for commodities and equipment (e.g. male and female condoms, vehicles), from staff training, and from publicprivate partnerships with international NGOs (social marketing campaigns for male and female condoms).

Several foreign universities are sponsoring programmes that supply capital goods, personnel, and policy development (biomedical interventions to reduce mother to child transmission; epidemiological studies of the impact of AIDS). Programmes working at the community level include peer education and behaviour change programmes, advocacy and policy development initiatives, support groups and organisations of people living with HIV, and service delivery, such as home based care.

One of the most visible programmes is the provision of voluntary counselling and testing for HIV. In March 1999, the government of Zimbabwe with assistance of international 
donors began a social marketing programme for VCT. By mid2000, 12 sites were opened. In the first year of services, over 6000 people were tested. Of those, approximately 19\% were HIV positive. Prevalence was significantly higher among women (Moses P, personal communication).

The multitude of programmes and projects in the country does not necessarily translate into an effective STI and HIV prevention effort. Few of the programmes include rigorous evaluations. Limited epidemiological surveillance data on STI make ecological appraisals (comparing infection rates in communities or groups before and after programme implementation) almost impossible.

\section{COMMENT}

Molecular epidemiology and network analysis of sexual partners offer new tools in understanding the natural history of STI. ${ }^{40-43}$ Although these are critical aids in understanding the transmission dynamics of particular pathogens, the focus on these proximal determinants of spread should not be at the expense of examination of more distal factors. Environmental factors including political and economic stability, employment, migration, as well as cultural and social norms, may in fact be more predictive of epidemic spread that other risk factors. UNAIDS has started to establish systems for "second generation surveillance," behaviour surveillance both to identify potential hotspots for HIV and to examine the success of prevention programmes. ${ }^{3}$ Perhaps a "third generation" surveillance is also in order to monitor the more distal determinants of the epidemiological profile of STI.

It is challenging enough to model the changing profile of individual and population risk considering determinants of risk on all the levels delineated in fig 1 . However, it is much more complex to conceptualise and predict the changes in the social, cultural, and political environment brought about by the progression of the epidemic, and to link this information to a changing risk profile. In the context of the HIV epidemic in southern Africa, it is particularly important to understand this dynamic, because it is certain that as the epidemic progresses through its phases of expansion, hyperendemicity, and regression, it will affect patterns of behaviour and influence the social, cultural, economic, and political environment of this region.

A focus on the ecological determinants of epidemic spread can lead to a certain level of nihilism. Public health professionals are usually quite realistic when assessing their influence on ending poverty, creating political stability, or preventing civil unrest. Nevertheless, it is possible to conceive of feasible strategies that address the more distal epidemic determinants of STI, especially when faced with a widespread, disseminated epidemic. This is not to say that they are only appropriate to a generalised epidemic. Many structural interventions, if successful, should have an effect not only on HIV and other STIs, but on other outcomes as well. Economic support programmes, for example, should attenuate the effects of poverty and thus increase standards of living regardless of infection risk. Such interventions would be applicable regardless of the phase of the epidemic and if in place, might make more epidemiologically driven targeted interventions directed towards individuals or subpopulations more effective. Given scarce resources, however, the optimal mix of structural interventions aimed at distal determinants versus interventions targeted at individuals most probably changes over the course of an epidemic, with the need for structural interventions increasing as the epidemic becomes more widespread.

Describing the social ecology of STI at the scale of an entire country, as we attempted in this paper, has major limitations because of the lack of homogeneity of populations and environments. It is clearly an exercise that would be more fruitful on a smaller scale-a district or a village. Similarly, structural intervention strategies would be more feasible when applied to a limited geographic and population scale in "community centred" programmes. In addition to interventions at the level of individuals these strategies may include (but not be limited to):

- Programmes that integrate prevention with care and social support; for example, by ensuring that appropriate referrals for services are in place before VCT programmes are established; offering one stop shopping for health care needs of individuals and families, and establishing a continuum from home care to orphan support to youth peer education programmes.

- Programmes that specifically focus on integrating and coordinating existing services and programmes at the delivery level.

- Programmes that focus specifically on ways to increase general communication and openness about sexual activity in general, and HIV and STI in particular. Having community leaders and politicians openly reveal their infection status, for example, could go a long way to reducing associated stigma, thus increasing discussion and disclosure.

- Programmes that evolve from existing social and service institutions outside government, for example involving religious institutions, the media, the entertainment industry, sports clubs, and so on.

- Economic support programmes including income generating and micro-credit programmes.

- Programmes that offer living accommodations for families in cities, mines, and the military. In fact several such programmes exist but without concomitant evaluations of their success in reducing infection rates.

- Programmes that focus on adolescents, preferably before they become sexually active.

\section{ACKNOWLEDGEMENTS}

Lisa Loeb in Harare collected and compiled most of the epidemiological and health service information and interviewed Zimbabwean government officials, international programme personnel, and researchers. Melanie LaPorte Smith in San Francisco searched and found references, edited, formatted, and did everything else necessary to coordinate the writing of this paper across 10 time zones.

\section{Authors' affiliations}

J Decosas, Southern African AIDS Training Programme, Harare, Zimbabwe

N S Padian, AIDS Research Unit, Department of Obstetrics and Gynecology, University of California, San Francisco, USA

\section{REFERENCES}

1 Blanchard J, Moses S, Greenaway C, et al. The evolving epidemiology of chlamydial and gonococcal infections in response to control programs in Winnipeg, Canada. Am J Public Health 1988;10:496-502.

2 Aral S, Holmes K, Padian N, et al. Overview: individual and population approaches to the epidemiology and prevention of sexually transmitted diseases and human immunodeficiency virus infection. J Infect Dis 1996;174:S127-33.

3 WHO/UNAIDS. Second generation surveillance for HIV: the next decade. Geneva: WHO/UNAIDS, 2000.

4 Thomas J, Clark M, Robinson J, et al. The social ecology of syphilis. Soc Sci Med 1999;48:1081-94.

5 Barnett T, Whiteside A, Decosas J. The Jaipur paradigm: a conceptual framework for understanding social susceptibility and vulnerability to HIV. South Afr Med J 2000;90:1098-101.

6 Government of Zimbabwe. Statistical yearbook. Harare: Central Statistical Office, 1997.

7 Economist Intelligence Unit. Zimbabwe country profile 1998-99. London: EIU, 1999.

8 United Nations Development Programme. Zimbabwe human development report. Harare: UNDP, 1998.

9 Economist Intelligence Unit. Zimbabwe country report June 2000 London: EIU, 2000

10 Government of Zimbabwe. Poverty assessment study survey 1995 Harare: Ministry of Public Service, Labour, and Social Welfare, 1999. 
11 Government, of Zimbabwe. Zimbabwe national health profile 1997. Harare: Ministry of Health and Child Welfare, Epidemiology and Disease Control Unit, 1997

12 UNAIDS. Epidemiological fact sheet on HIV/AIDS and sexually transmitted diseases. Geneva: UNAIDS/WHO Working Group, 2000.

13 Government of Zimbabwe. National census report. Harare: Central Statistical Office, 1992

14 Government, of Zimbabwe. Inter-census demographic survey report. Harare: Central Statistical Office, 1997.

15 Ncube W, Stewart JE, Kazembe JL, et al. Continuity and change: the family in Zimbabwe. Harare: Women and Law in Southern Africa Research Project, 1997.

16 Weinrich AKH. African marriage in Zimbabwe and the impact of Christianity. Gweru: Mambo Press, 1983.

17 Bourdillon M. The Shona peoples. Gweru: Mambo Press, 1987.

18 Gregson S, Nyamukapa C, Mlilo M. Are women or men more affected by HIV in Southern Africa? Insights from studies in rural Zimbabwe: SAfAIDS News 2000;8:2-7

19 Singh S, Wulf D, Samara R, et al. Gender differences in the timing of first intercourse: data from 14 countries. Int Fam Plan Perspect 2000;26:21-43

20 Clinical Epidemiology Unit, University of Zimbabwe and FHI. Behavioural surveillance for HIV/STD risk-related behaviours. Preliminary findings (unpublished report)

21 Vos T. Attitudes to sex and sexual behaviour in rural Matabeleland, Zimbabwe. AIDS Care 1994;6:193-203.

22 Wilson D, Manual A, Lavelle S. Personality characteristics of Zimbabwean men who visit prostitutes: implications for AIDS prevention programmes. Personality Individual Diff 1992;13:275-9.

23 van de Wiigert J. The effect of douching, wiping, inserting herbs inside the vagina, on the vaginal, and cervical mucosa on the vaginal flora and on the transmission of human immunodeficiency virus and other sexually transmitted diseases in women in Zimbabwe. Berkeley: University of California at Berkeley, 1997. [Dissertation.]

24 Wilson D. Mutero C, Lavelle S, et al. Sex worker, client sex behaviour, and condom use in Harare, Zimbabwe. AIDS Care 1989;1:269-80.

25 Government of Zimbabwe. Zimbabwe Demographic and Health Survey 1999 (preliminary report). Harare: Central Statistical Office, in conjunction with Measure DHS, Calverton, Maryland, USA, 2000.

26 Gregson S, Zhuwau T, Anderson RM, et al. Is there evidence for behaviour change in response to AIDS in rural Zimbabwe? Soc Sci Med 1998;46:321-30.

27 Olayinka BA, Alexander L, Mbizvo MT, et al. Generational differences in male sexuality that may affect Zimbabwean women's risk for sexually transmitted diseases and HIV/AIDS. East Afr Med J 2000;77:93-7.
28 Brown JE, Brown RC. Traditional intravaginal practices and the heterosexual transmission of disease: a review. Sex Transm Dis 2000;27:183-7.

29 Ray S, Gumbo N, Mbvizo M. Local voices: what some Harare men say about preparation for sex. Reprod Health Matters 1996;7:34-45.

30 van de Wijgert J, Chirenje Z, lliff V, et al. The effect of intravaginal practices on the vaginal and cervical mucosa of Zimbabwean women. $J$ Acquir Immune Defic Syndr Hum Retrovirol 2000;24:62-7.

31 Report on the City Health Department. Harare, Zimbabwe: City Health Department, 1999

32 Taha TE, Hoover DR, Dallabetta GA, et al. Bacterial vaginosis and disturbances in vaginal flora: association with increased acquisition of HIV. AIDS 1998;12:1699-706.

33 Martin HL, Richardson BA, Nyange PM, et al. Vaginal lactobacilli, microbial flora, and risk of human immunodeficiency virus type 1 and sexually transmitted disease acquisition. J Infect Disease 1999:180:1863-8.

34 Van de Wiigert J, Fullem A, Kelly C, et al. Phase I trial of the topical microbicide buffer gel: safety results from four international sites. J Acquir Immune Defic Syndr 2001;26:21-7.

35 Mbizvo MT, Machekano R, McFarland W, et al. HIV seroincidence and correlates of seroconversion in a cohort of male factory workers in Harare, Zimbabwe. AIDS 1996;10:895-901

36 Humphrey J, lliff $P$, Nathoo K, et al. Rationale and design of the ZVITAMBO trial (Zimbabwe vitamin a for mothers and babies). XIII International AIDS Conference. Durban, South Africa, 2000.

37 Mason PR, Gwanzura L, Latif AS, et al. Antimicrobial resistance in gonococci isolated from patients and from commercial sex workers in Harare, Zimbabwe. Int J Antimicrob Agents 1998;9:175-9.

38 HERA. Review of the Health Sector of the Republic of Zimbabwe. Reet Belgium: Health Research for Action, Ministry of Health and Child Welfare and European Commission, 1997.

39 UNAIDS. Inventory of Donor Assistance to the HIV/AIDS Sector in Zimbabwe. Harare: 1999.

40 Scribner $\mathbf{R}$. The end of the chronic disease era. Am J Public Health 1997:87:872-3.

41 Susser M, Susser E. The legacy of epidemiology in the department of social and preventive medicine: a commemoration of the sesquicentennial of the State University of New York at Buffalo School of Medicine and Biomedical Sciences. Am J Epidemiol 1999:11:1072-3.

42 Ambrosone C, Kadlubar F. Toward an integrated approach to molecular epidemiology. Am J Epidemiol 1997; 146:912-18.

43 McMichael A. Invited commentary - "molecular epidemiology": new pathway or new travelling companion? Am J Epidemiol 1994;1:1-11. 